Article

\title{
Serious Game iDO: Towards Better Education in Dementia Care
}

\author{
Rytis Maskeliūnas 1,2 (D), Robertas Damaševičius ${ }^{1,2, * \mathbb{D}}$, Connie Lethin ${ }^{3,4}$ (D), \\ Andrius Paulauskas ${ }^{2}$, Anna Esposito ${ }^{5}$ (D) Mauro Catena ${ }^{6}$ and Vincenzo Aschettino ${ }^{6}$ \\ 1 Institute of Mathematics, Silesian University of Technology, Kaszubska 23, 44-100 Gliwice, Poland; \\ Rytis.maskeliunas@polsl.pl \\ 2 Faculty of Informatics, Kaunas University of Technology, Studentu 50, 51368 Kaunas, Lithuania; \\ andrius.paulauskas@ktu.lt \\ 3 Department of Health Sciences, Faculty of Medicine, Lund University, SE-221 00 Lund, Sweden; \\ connie.lethin@med.lu.se \\ 4 Clinical Memory Research Unit, Department of Clinical Sciences, Lund University, SE-221 00 Lund, Sweden \\ 5 Università Vanvitelli, Dipartimento di Psicologia; Viale Ellittico, 31-81100 Caserta, Italy; iiass.annaesp@tin.it \\ 6 Tech4Care, Via Guglielmo Marconi, 31, 60015 Falconara Marittima AN, Italy; \\ mauro.catena@gmail.com (M.C.); v.aschettino@tech4care.it (V.A.) \\ * Correspondence: robertas.damasevicius@polsl.pl
}

Received: 8 October 2019; Accepted: 16 November 2019; Published: 18 November 2019

check for updates

\begin{abstract}
We describe the iDO serious game developed during implementation of the Innovative Digital Training Opportunities on Dementia for Direct Care Workers (IDO) project. The project targets formal and informal caregivers of persons with dementia in order to improve caregiver knowledge and competences skills with a non-traditional source of training. This paper describes the steps faced to define the iDO caregiver behavior improvement model, design of game mechanics, development of game art and game characters, and implementation of gameplay. Furthermore, it aimed to assess the direct impact of the game on caregivers $(n=48)$ and seniors with early signs of dementia $(n=14)$ in Lithuania measured with the Geriatric Depression Scale (GDS) and Dementia Attitudes Scale (DAS). The caregivers' GDS scores showed a decrease in negative answers from $13.4 \%$ (pre-game survey) to $5.2 \%$ (post-game survey). The seniors' GDS scores showed a decrease in negative answers from $24.9 \%$ (pre-game survey) to $10.9 \%$ (post-game survey). The overall DAS scores increased from 6.07 in the pre-game survey to 6.41 in the post-game survey, statistically significant for both caregivers and seniors $(p<0.001)$, respectively. We conclude that the game aroused positive moods and attitudes for future caregivers of persons with dementia, indicating a more relaxed status and a decreased fear in accomplishing the caring process.
\end{abstract}

Keywords: assisted living; dementia care; people with dementia; caregivers; information and communication technology; educational game; serious game

\section{Introduction}

Active and assisted living solutions can have a positive influence on the health and quality of life of older people. Information and communication technologies (ICTs) can target the following care problems targeted at people with depression and/or chronic disease [1,2] limitations in daily activities, chronic diseases, fall risk, dementia, depression, social isolation, and poor medication management.

Dementia is emerging as one of the most common age-related diseases with an estimated 74.7 million people having different forms of dementia-related diseases by the year 2030 [3]. The disease causes many changes in the behavior of persons with dementia depending on the degree of severity, as for example, the forgetting of how to use appliances, misplaced sense of time and space, getting particularly suspicious, 
impressionable, frightened, and vision and hearing can also be affected [4]. Being the caregiver of a person with dementia can be extremely hard, since the person with dementia can no longer tell you how she feels or what she perceives. Caregivers need to enhance their listening skills and pay attention to the behavior of a person with dementia in order to perceive communicative signals from them.

The difficulty in being a caregiver of a person with dementia is that the person's behaviors undermine all the basic, social, and interactional conducts which were learn throughout our lives as members of society. Simple daily speech and associated gestures like "please" and "thank you" may disappear, and, indeed, the person with dementia may even violently reject any care from both formal and informal caregivers. Daily routines for those caring for people with dementia who are more or less independent may be complicated and a source of high stress, to the extent that caregivers may end up losing their temper and immediately regret it, an alternation of moods which is no good for either of them. There are no rules nor manuals to follow, since each situation is a different case in itself.

Dementia cannot be cured, while drugs target only the symptoms rather than the causes of the disease. New technologies based on the use of ICT technologies are being considered to improve communication skills and reduce associated stress both for people with dementia and for caregivers [5]. Creation of emotional involvement, determination, and full immersion in the process, which sometimes makes you forget about time, in cases of virtual reality can help to increase the effectiveness of professional caregiver training.

Serious games are among the suitable tools to assess improvements in motor-cognitive performances, transfer training outcomes of a curative task to new untrained tasks, and to sustain training gains [6] in people with dementia and their formal and informal caregivers. We designed an interactive mobile serious game aiming to allow caregivers to manage, a series of real world-based scenarios for dementia care and learn how to apply the problem-solving activities virtually developed to their daily routines. The game is hosted at the iDO project's website [7]. This paper elaborates on our previous work and experience presented in Reference [8].

\section{Related Concepts on Serious Games}

\subsection{A Potential in Serious Games and Gamification}

Increasing motivation is one of the main aims of introducing gamification into serious contexts [9]. Empirical evidence exists showing the efficiency of gamification and serious games. A survey [10] showed the relationship between utilitarian, hedonic, and social motivations and continued use intentions, suggesting that a benefit is mediated by the attitude toward the use of gamification, while hedonic aspects have a direct positive relationship. On the other hand, social aspects affect attitude which is an important factor to consider when targeting specific audiences [10] such as people with dementia. According to a review presented in Reference [11], application of the gamified learning concepts to traditional educational media can improve learning outcomes. A study [12] showed that many test subjects preferred the game delivery format to all other education formats they had experienced.

Games for learning were successfully used to bolster knowledge acquisition in different domains (such as preschool education [13], project-based teaching at university [14], and economics and marketing education [15]) while supporting, to a lesser degree, sustaining work productivity [16] and the acquisition of new knowledge [17], social skills, and behavioral changes [18]. The exploitation of such ICT interfaces allows educators to envisage new and innovative teaching methods such as, for example, preparing medical professionals to explore new therapies and medical procedures, putting people at lesser risk, as it was shown that older people who use computers have a lower risk of receiving a diagnosis of dementia by up to 8.5 years [19]. This will allow practitioners to acquire new evaluation, detection, scrutinizing, and observational abilities and awareness of how these abilities affect their acting in daily real-life circumstances [20]. The modeling of real situations can be used for training practitioners on how to react to dynamic evolving events, improving, as consequence, the quality of their performance, even saving, in medical practices, the life of a person under care. Concurrently, awarding a player with 
scores (or badges) for each right decision made in the game can be an effective way to involve her in the training process, encouraging lifelong learning [21]. Researchers illustrated the effectiveness of this approach through a video-based serious game created for nursing students on caring for persons with pulmonary disease [22].

Serious games are often applied in the health domain in ever-growing rates $[23,24]$. Such games can contribute to improving daily management of neuropsychiatric symptoms (NPS) and, eventually, to improving the psychological state and satisfaction of both persons with dementia and caregivers [25]; thus, the iDO serious game targets the caregivers of persons with dementia and not the people with dementia themselves. In this context, virtual gaming associated with hands-on simulations has become a measure of the best teaching and learning practices, improving parameters of caregiver's professional knowledge and self-satisfaction [26], while more common games are aimed at the person with dementia directly (e.g., memory games, cognitive skills development, etc.). The consequential advantages of the best care practices can serve to provide improvements in motivation, decision-making, and even financial value [27]. The related studies on serious games dedicated to dementia [28,29] did not target dementia caregivers themselves.

\subsection{Serious Games in Health Care}

A range of core competencies can be developed using a dedicated serious game in nursing education [30]: procedural, health assessment, communication, and clinical reasoning skills. Serious games can be applied to support virtual training, such as clinical virtual simulation [31], and can provide a pedagogical strategy and work as a supplement to real-life alternatives and provide increased situational awareness [32]. A statistically significant difference was found between the competence of groups that played a simulation game and those that trained traditionally in life support exercises [33]. Tresser [34] showed that it can also work as a tool for occupational therapy, successfully testing the concept on patients diagnosed with dyspraxia-impaired postural structure. According to Johnsen et al. [35], a serious game can be considered useful, usable, and satisfying while improving the reasoning and decision-making skills of nursing students. Games with creativity support can be applied to train caregivers in creativity techniques in order to deliver more person-centered care to people with dementia [36]. Transcultural aspects can also be explained through in-game dialogues and other forms of simulations [37].

The gamified modelling of some of the caregiver aspects was already explored in certain aspects. Patel and Salata [38] investigated the simulation of caregiver-child communication for children with severe dysarthria, proving that a simple interface of sound tonality can change the coadaptation and helps to better understand each other. Similarly, a serous game helped to understand the engagement of children with unilateral cerebral palsy [39] reducing caregiver involvement. As an alternative, serious games can be used to measure acceptance and effectives in decision making which is essentially important in nursing services [40].

Another major feature of serious games is the possible application for rehabilitation. Wingham et al. [41] illustrates such a concept with the application of a Wii sports games for stroke survivors, proving that gamified motion training can lead to an improvement of the originally impaired arm motoric. A Kinect-based approach [42] showed positive effects on the functional abilities of self-care, mobility, and social function with disabilities that were very significant.

Nursing of people with dementia can utilize computer-based cognitive stimulation and other enjoyable activities to increasing care satisfaction [43]. This was proven by Tong et al. [44] who showed that people with cognitive impairments may benefit from playing serious games, potentially assessing a variety of factors associated with cognitive decline in dementia, while keeping individuals active and stimulated thereby potentially slowing down or furthering cognitive decline [44]. Social engagement was illustrated by the Walk2Win game [45], showing that game users expressed a strong preference and interest in building a team. 


\section{Serious Game Design}

\subsection{Educational Model for Knowledge Transfer by iDO Gameplay}

Evolving from a combination of traditional e-learning and gamification, serious games can work as different standalone training solutions for doctors, formal and informal caregivers, and persons with dementia as was evolved by usability assessment studies [46] showing that a fulfillment of a specific task highly depends on the task itself and on the abilities of the subjects, making the concept especially challenging. The iDO educational models on which the idea of the game was based derived from the e-health gamification best practices [47], proving that to yield solely short-term engagement is mostly possible through extrinsic rewards. For a serious game to reach its full potential, the game must be built with e-health scenarios in mind, exploiting the core experience and psychological effects of game mechanics. This idea was applied on the behavior model of rehabilitation by Wiemeyer et al. [48] including physiological, psychological, social, and sensory-motor factors, where an advantage is noticeable if the game interventions are to be developed and evaluated based on the individual prerequisites. This was confirmed by the flowchart scenarios of Elaachak et al. [49] depicting that the most efficient environment of a serious game is often that which is similar to the real one, so the learner can envisage different solutions more easily (applied to nursing which also applies to the iDO game); for each right decision the player gains a set of points that are required to reach an objective. This idea was further expanded following a concept proposed by Reference [50], where the game offers both a player situational analysis and evaluation capability and a situation development and outcome evaluation capability, a feature which we decided to adopt and follow.

Our model (displayed in Figure 1) was based on the idea of the project to supplement the materials offered within the iDO massive open online course (MOOC), which had interactive scenarios only possible in the serious game format, in order to facilitate the three main goals which were established following the best practices of Reference [51]:

1. To increase cognitive skills by teaching the concepts and principles of dementia care thus understanding differences among persons with various degrees of dementia and to demonstrate the ability of applying concepts to solve various real-life situations (via solving in-game problems), enhancing knowledge retention.

2. To increase behavioral skills (care practice and development) to allow a more effective factual implementation of dementia care concepts, practical familiarization with problems, and outcomes and consequences through in-game decision making thus improving situational awareness, analysis, and decision skills.

3. To increase skills to improve overall attitudes, motivation, and engagement towards dementia care not excluding the increase in overall job satisfaction.

The iDO education model strives to gently feed the situations, requiring learning a specific set of know-how and background knowledge to solve a random or scenario-based gameplay situation (practice of skills). The game always ends when the quality of life bar reaches zero (0). Gameplay (game outcomes) only influences how fast and with what consequences (e.g., simulated quality of life) it will be reached. The game itself forces the caregiver to learn how to care for elderly relatives or persons with dementia. Each game outcome also unlocks a story aspect, often used to educate a peculiar aspect within dementia care. Mission solving in a game (resulting in an outcome) serves as an evaluation tool, where the game itself does not give an in-game guidance on how to tackle a peculiar problem but refers a player to the course learning materials. The gameplay constantly forces a player to refer to the training materials (orange arrow) and use the newly gained knowledge (yellow arrow) to progress. 


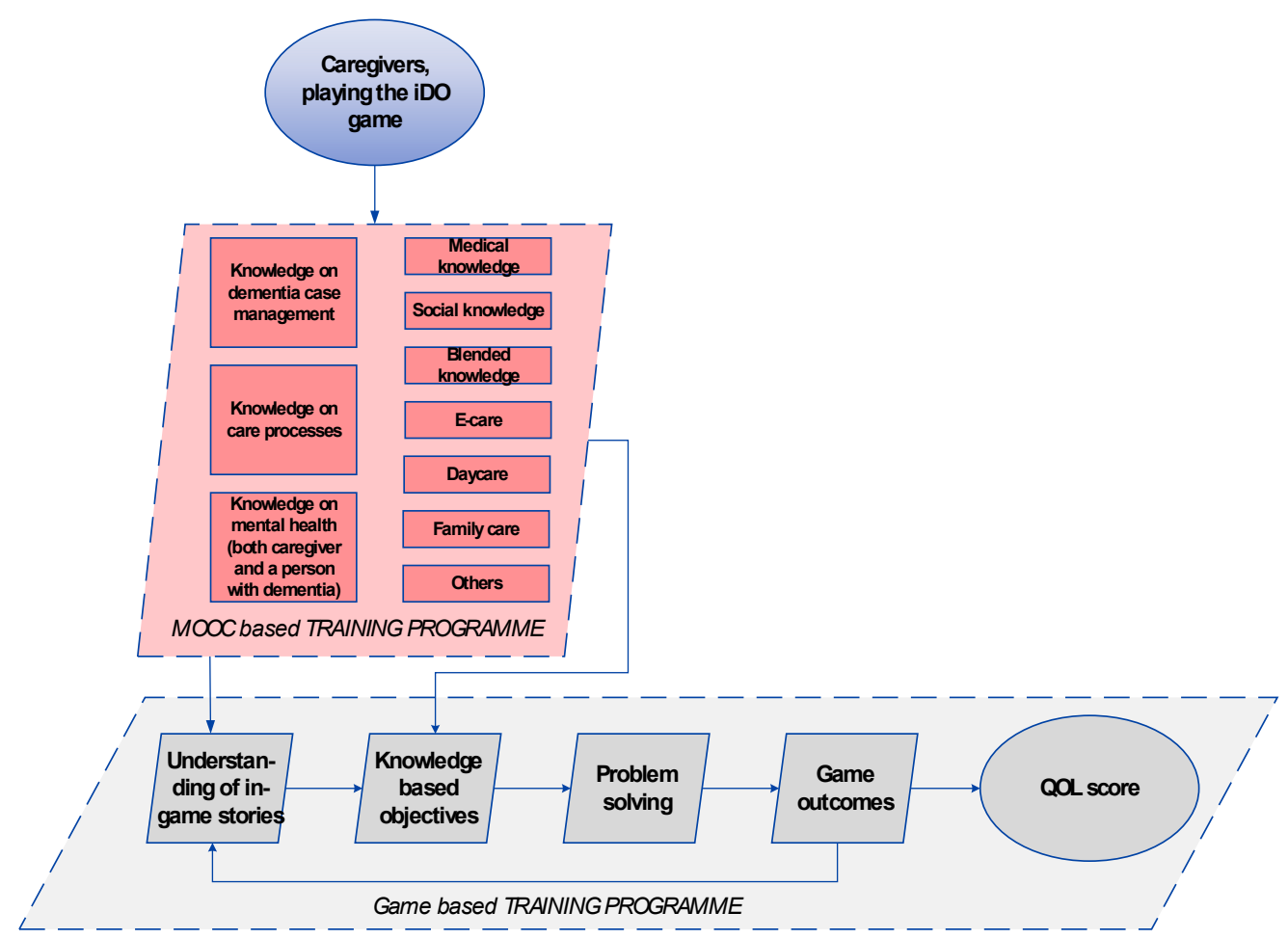

Figure 1. Educational model for the iDO gameplay. MOOC - massive open online course. QOL Quality of Life.

\subsection{Model of Game Mechanics}

The idea of the game mechanics was based on an adaptation of the Tamagotchi and SIMS (Electronic Arts Inc. (EA)) series of games, where players take care of their virtual entities. The game progresses through the character's daily life, where he/she is mostly independent, requiring the player's interaction only to control more efficiently the character's needs (Figure 2). For the simulation of a social interaction, the model of the game mechanics provides a simple dialogue, where the player communicates with his game character, inquiring about his experience, etc.

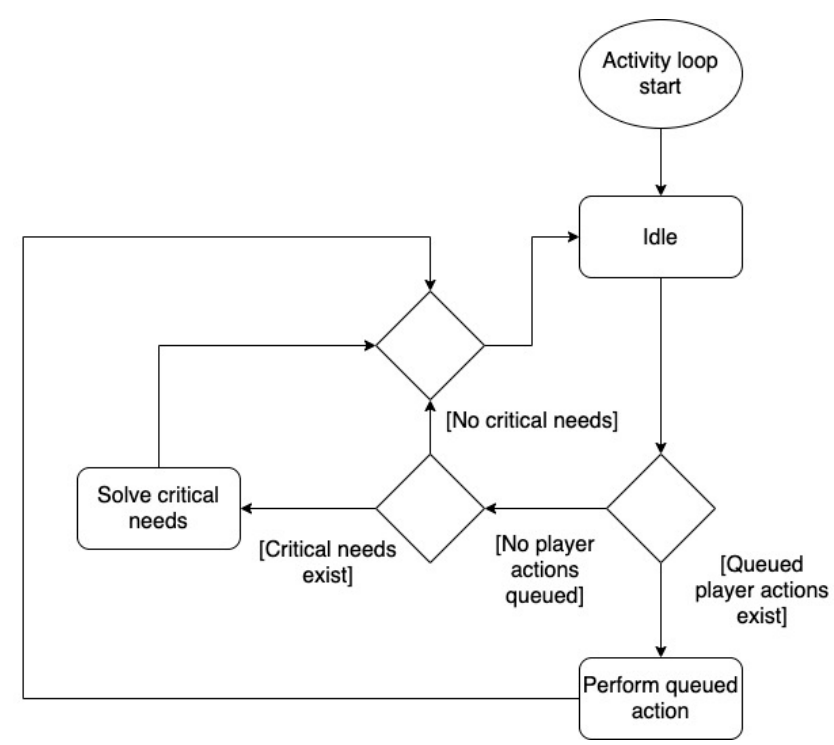

Figure 2. Basic activity loop of the game character. The game character is, most of the time, strolling idly, acting only when the player queues or when the character must act in solving a need that reaches critical thresholds. 
Our knowledge-based game mechanics [52] were based on the simplified needs system adopted by the SIMS games (the simulation model is illustrated in Figure 3). Each game character's needs can be represented as a resource that is periodically drained. Performing an action fulfils a need and replenishes the resource but can also have side effects on other values tracked in the game. The needs in the game are as follows:

- Rest shows the tiredness rate of the person. This value is reduced over time and increases automatically when the person is resting. The reduction rate is increased when the person participates in activities, which increases the fun value.

- Hunger represents the character's need for food. The value representing hunger is increased and reduced automatically whenever the person eats.

- The fun value shows the overall happiness and positive engagement of the game character. This value decreases over time. However, participating in fun activities increases the value.

- The social interaction value shows the need of a person for socialization. This value is increased when the person chats with the game character.

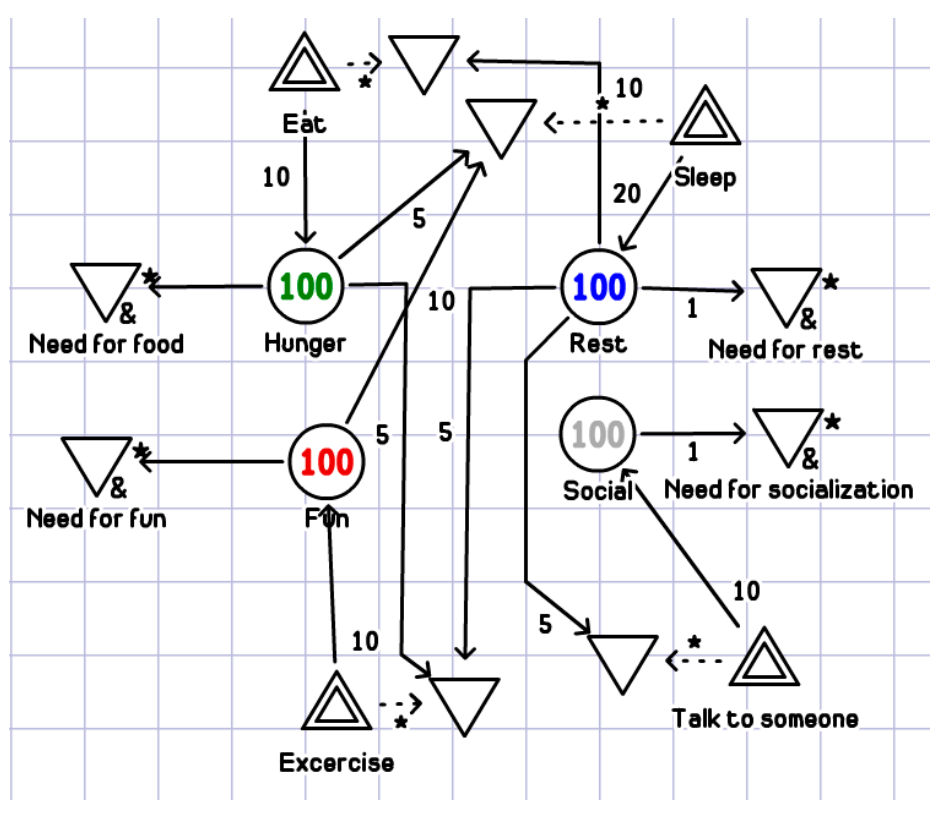

Figure 3. Model of the person with dementia's needs and actions.

The overall well-being of the character is represented by the fun value, which decreases as time passes but can be increased when resting or interacting socially.

The described needs and relationships among the needs are visualized in a machinations [53] diagram, a visual language for describing gameplay rules and mechanics shown in Figure 3 . The four needs are defined as resources stored in a resource pool. They are each passively reduced by a drain node connected to each resource. An interactive source node is also connected to each resource pool which represents actions that need to be solved. These actions reduce a specific need but may also increase other needs.

The game's inner state is defined by three groups of variables: independent, intermediate, and dependent. Independent variables do not change throughout the game, while their values are randomly assigned from given sets at the beginning of the game. The intermediate and dependent variables change over the course of the game. The way that intermediate variable values change is affected by the values of independent variables and can also be influenced by the player's actions in the game. The values of the dependent variables depend solely on the values of intermediate variables. From this definition, a relationship emerges among the three different groups. 
As mentioned before, independent variables are randomly assigned at the beginning of the game. These variables include gender, socio-economic status, nationality, and the age of the person with dementia which the player must take care of. Values of each of these variables will define how the intermediate variables' values change. Intermediate variables are separated into two groups: basic needs and psychological needs. Basic needs include hunger, rest, mood, and hygiene. Psychological needs include functional abilities (activities of daily living (ADL), instrumental ADL (IADL)), behavioral disturbances (neuro psychiatric inventory, NPI), and distress (NPI-D). These needs passively change over time. The change rate is affected by the independent variables' values. Significant changes in the need variable values occur concurrently with player actions. For example, the person with dementia (character) gets increasingly hungry over time, and the hunger is diminished by the player telling the character to go and eat.

The dependent variables are intended to describe the player's scores which specify how well the player is taking care of his character. These variables are defined as quality of life and vital status. A character with neglected needs will have a lower value quality of life score, and it is the player's responsibility to improve it by helping the character fulfill his needs. In such a way, a direct relationship between intermediate and dependent variables is defined. This game model is illustrated in Figure 4 and explains the concept of game avatar (person with dementia) reacting to various game situations (which are handled through in-game dialogues).

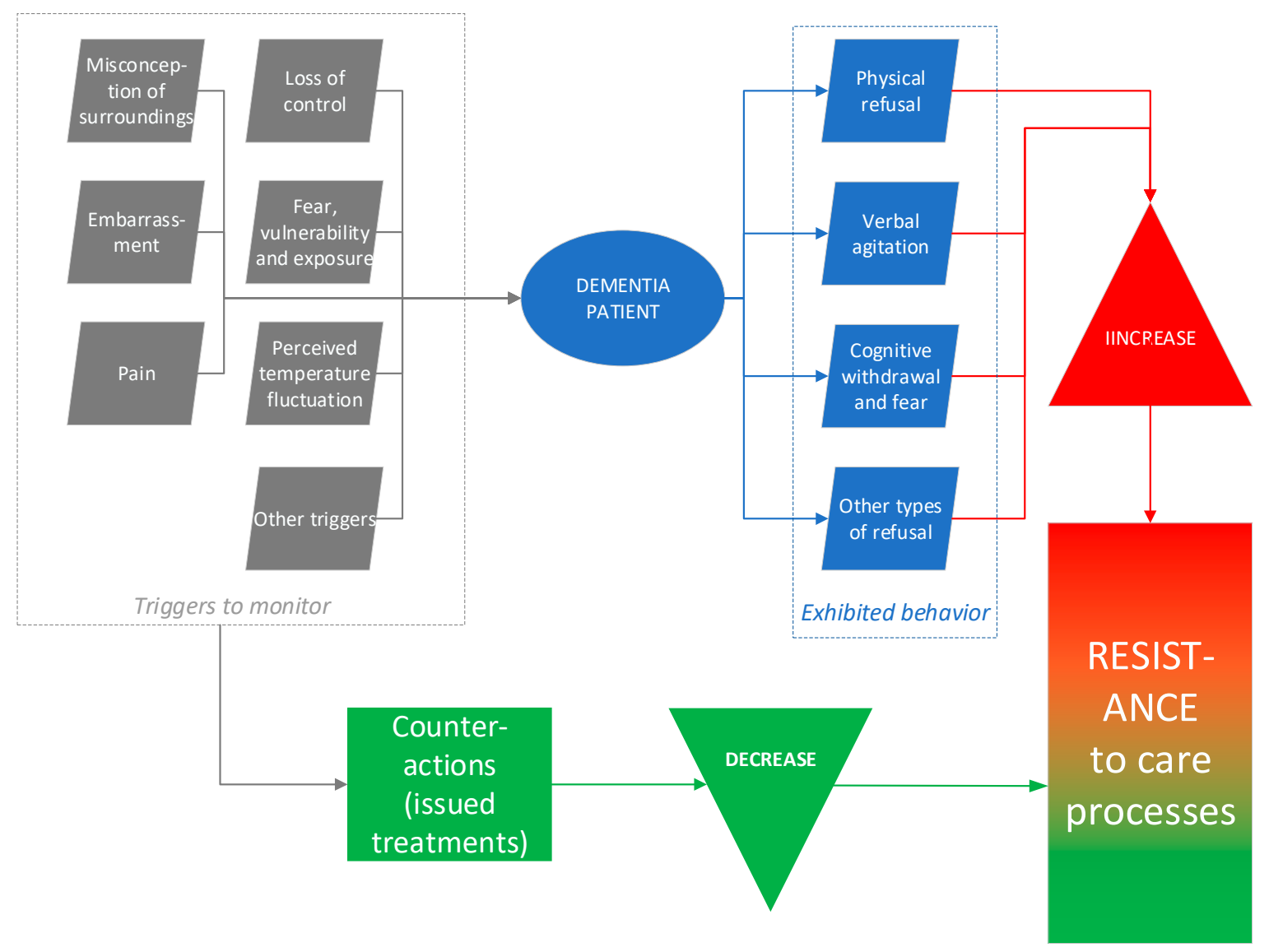

Figure 4. Game model of the avatar's (person with dementia) reaction to care processes.

The evolution of the game is defined by the time and effort spent taking care of the game's character. There are no penalties envisioned, as the game is intended to provide a relaxed, stress-free environment. The game does have unlockable levels which are rewarded upon various stages of the MOOC completion. This is used as an opportunity to integrate the game with the learning environment in such a way that levels are unlocked after educational activities are completed in a learning environment. The game also 
provides feedback so that playing the game can be counted as a learning activity within the learning environment. The add-ins include purely decorative items, such as wallpapers, which can be modeled according to the above-described activities and the person with dementia's needs.

\subsection{Model of Game User Experience (UX)}

Game user experience was developed together with specialists in the area. Through feedback exchanged between medical professionals and a user experience/user interface (UX/UI) designer, the first design of the game characters turned out to be more like caricatures and would not arouse the desired light and easy-going mood of the game (Figure 5a). The final iteration of the design resulted in cleaner characters (Figure $5 b$ ). In-game animation helps the game characters reveal their personalities therefore reaching the desired look and feel of the game.

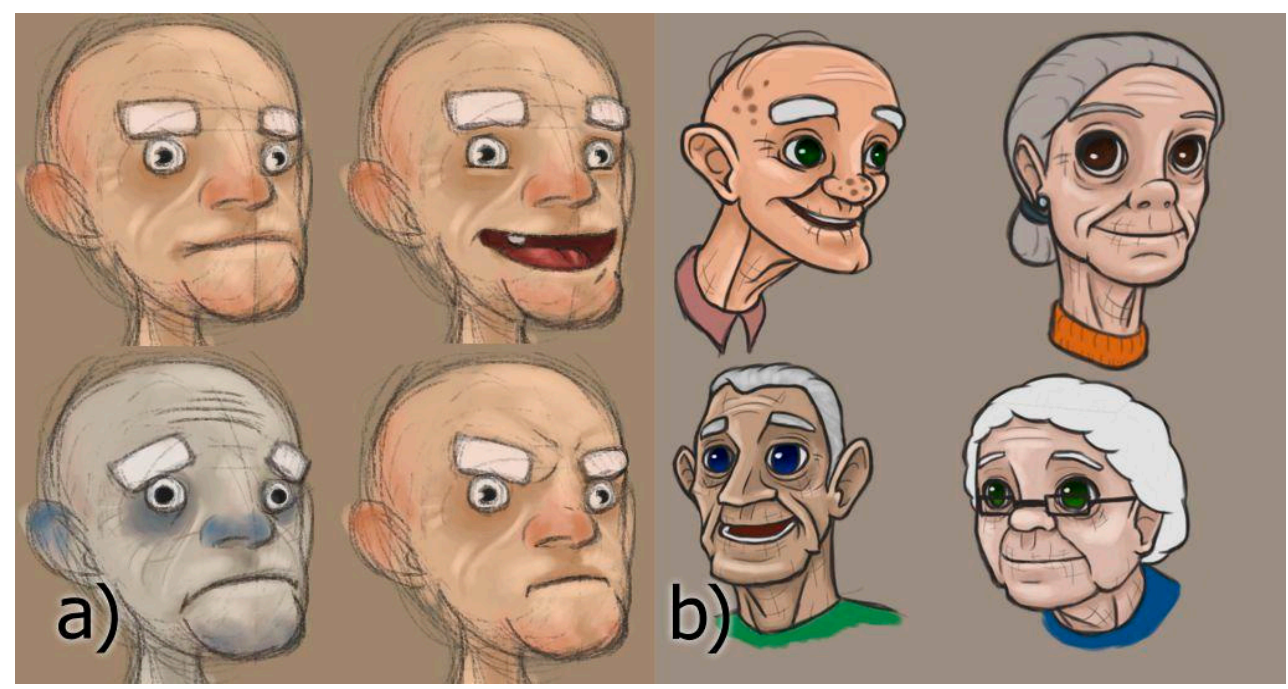

Figure 5. (a) Initial character concepts. (b) Final character concepts.

Initially, the environment showed some exaggeration in the forms and colors as well as the characters, (Figure 6a) which caused confusing interpretations by different people and overcomplicated the game. The redesigned game uses simple and realistic object shapes with bright colors to achieve a positive mood (Figure $6 b$ ).

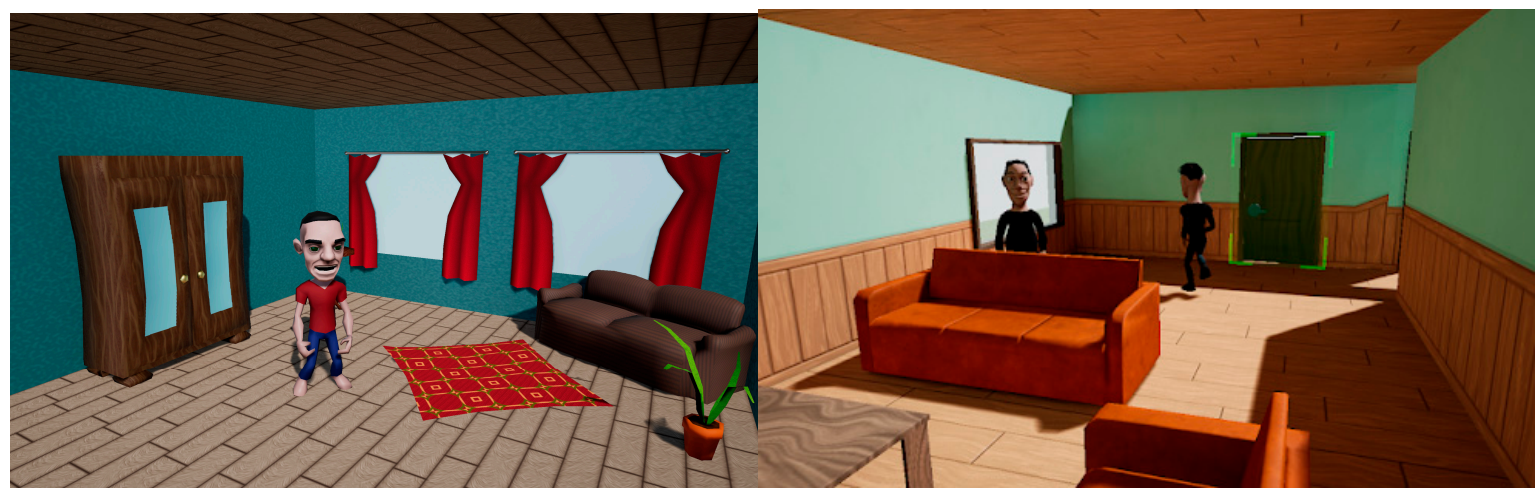

(a)

(b)

Figure 6. (a) Initial user experience (UX) concept. (b) Final UX design.

We used the standard framework of gameplay provided by the Unreal Engine 4 (Epic Games, SC, USA). All objects in the game world are defined as actors, while the Game Mode actor defines the 
rules of the game. The physical representations of the Controller actors are called the pawns. The AI Controllers control the pawn with the game engine's artificial intelligence implementation.

The game is controlled and influenced by six main actors (Figure 7):

1. Player Controller, also interacting with these activity entities, guides the Patient Character to do the activities associated with them and to interact with the activity entities.

2. Character Creation Pawn presents the player with the character customization user interface and has a reference to the Patient Character to allow its customization.

3. Game Pawn is controlled by the Player Controller and includes camera manipulation functions to allow the player to observe the game world from various points of view.

4. Patient Character is the pawn that represents the patient that the caregiver has to look after. This pawn's behavior is controlled by the AI Controller.

5. AI Controller is driven by the AI system based on behavior trees in order to controls the Patient Character's behavior.

6. Activity Entities are objects in the game world, such as the couch on which the character can rest, and with which the player can interact with it during the gameplay.

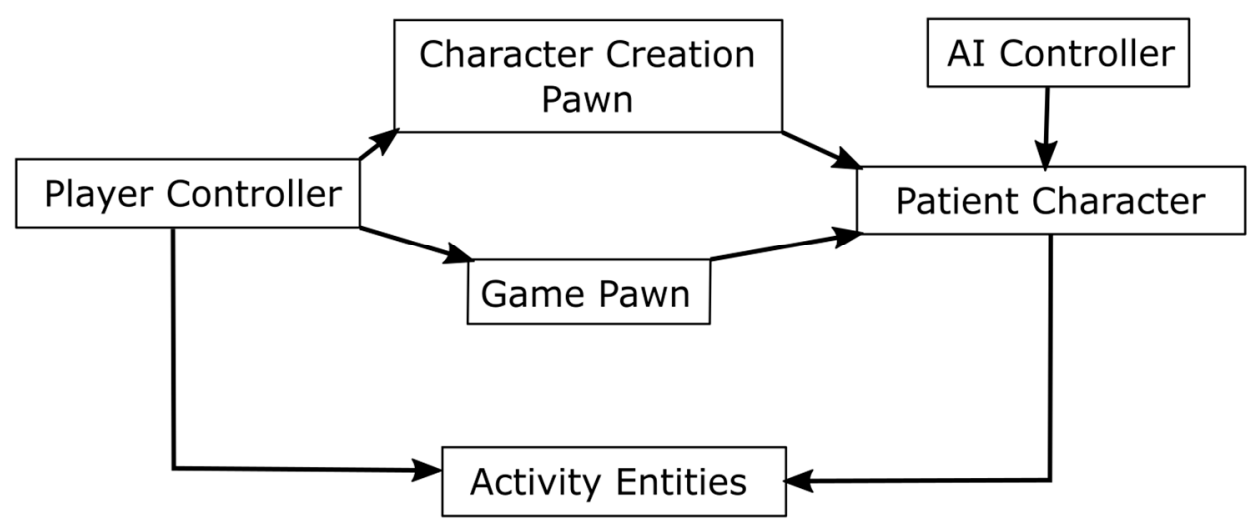

Figure 7. The game's main actors and the relationships among them.

\section{Methods of Evaluation and Results}

The survey included 12 social care workers (age 42-71), 36 non-professional caregivers (caring for their family members) (age 26-62), and 14 seniors with early signs of dementia (age 68-95) in Lithuania's Kaunas region. The participants of the survey were recruited in cooperation with the Geriatric Clinic of the Lithuanian University of Health Sciences.

Following the methods developed by Carpenter et al. [54], a pre/post survey design was adopted (post-game survey followed 4 months after the pre-game survey), and the perceived anxiety of seniors and their caregivers (family members and care workers who interact frequently with the elders) was assessed through the 30 item Geriatric Depression Scale (GDS) [55]. The caregivers and seniors were separately assessed. The results of the survey are summarized below.

In the caregiver group, the percentage of negative answers decreased from $13.4 \%(\mathrm{SD}=1.0)$ in the pre-game survey to $5.2 \%$ ( $\mathrm{SD}=0.5$ ) in the post-game survey. Note that we do not separate between formal and informal caregivers. In the senior group, the percentage of negative answers decreased from $24.9 \%(\mathrm{SD}=1.7)$ in the pre-game survey to $10.9 \%(\mathrm{SD}=0.9)$ in the post-game survey. The results between the pre-game survey and the post-game survey were statistically significant both for the caregivers $(t$-test $p<0.001)$ and the seniors $(t$-test $p<0.001)$.

To evaluate the cognitive, behavioral, and affective elements of an attitude toward the caregivers, the 20 item Dementia Attitudes Scale (DAS) [56] was pre- and post-administered to the original set of the caregivers of the seniors $(N=48$ subjects). Each item was assessed using a 7 point Likert scale ranging from 7 (strongly agree) to 1 (strongly disagree), while half of the items were reversely scored. 
The initial score of the group of $65.3 \%$, indicating confidence in being around people with dementia ("I feel confident around people with Alzheimer's disease and related disorders" (ADRD)), increased by $14.32 \%$ ( $S D=1.2$ ). The initial score for the group of $19.44 \%$, indicating a care process as uncomfortable ("I feel uncomfortable being around people with $\mathrm{ADRD}$ "), decreased by $6.9 \%(\mathrm{SD}=1.41)$, proving the seriousness of considering an iDO game-based approach.

The DAS also showed a quite significant change in attitudes, particularly on feeling more relaxed ("I feel relaxed around people with ADRD") and less frustrated ("I feel frustrated because I do not know how to help people with $\left.\mathrm{ADRD}^{\prime \prime}\right)$, by $14.7 \%(\mathrm{SD}=0.8 \%)$ and $17.2 \%(\mathrm{SD}=0.91)$ compared to the original scores of $48 \%$ and $53 \%$, respectively.

The DAS survey of the family members of seniors and social care workers indicated a decrease in the permanent care of a person with dementia (note: not considering financial obligations which, however, are very important in households with a lower income). The overall reduction in fear for all caregivers was significant, by at $18 \%(\mathrm{SD}=1.4 \%$ ) (as compared to the original value of $76 \%$ ).

The overall results of the DAS survey are summarized below. Total scores in the pre-game survey ranged from 5.53 to 6.33 (mean $=5.94 ; \mathrm{SD}=0.21$ ) and increased from 6.07 to 6.41 (mean = 6.28; $\mathrm{SD}=0.08)$ in the post-game survey, indicating that attitudes were generally positive. The results between the pre-game survey and the post-game survey were statistically significant for both caregivers ( $t$-test, $p<0.001)$ and seniors ( $t$-test, $p<0.001)$.

We also used the well-known System Usability Scale (SUS) questionnaire [57] in order to gather user feedback and quantitatively evaluate system usability (UX) properties. Each participant was administered a 10 item questionnaire, and each item was evaluated on a 5 point Likert scale [58]. The questionnaire was filled by every participant after playing the game for $20 \mathrm{~min}$.

Caregivers rated the game very positively with an average score of 79.75. The healthy elderly participants rated the software with a score of 73, which is still above the average SUS score of 68 . The last group—elderly with signs of dementia—rated the software poorly, attributing to the system a score of 56.25. The lower SUS score can be explained by some elements of the game placing a burden on the cognitive abilities of people with dementia, which is in agreement with the results of other similar studies [59].

Before evaluating the responses to each SUS item, let us consider the role they played in the system evaluation. Every odd numbered item (1st, $3 \mathrm{rd}$, 5 th, etc.) is formulated as a positive statement, thus it is desirable that odd numbered SUS items receive high scores (i.e., 4 or 5) while every even numbered item is formulated as a negative statement making low scores more desirable.

The average scores of each SUS item (according to its number) for the caregiver group are reported in Figure 8. Figure 8 shows that learning how to use the software was not complicated; the response to item 7 ("I would imagine that most people would learn to use the software very quickly") was rated 4.75 on average, which means that respondents strongly agreed with this statement. Similarly, the rating of items 4 and 10 related to the system's learnability ("I think that I would need the support of a technical person to be able to use the software" and "I need to learn a lot of things before I could get going with the software") was rather low on average, reaching a score of 1.92, reinforcing the concept of the ease of use of the proposed software. In addition, the game users declared that they were very confident in using the proposed software (item 9 , rated 4.13 on average). However, the desire to use the software frequently (item 1) scored rather low-only 2.92 on average.

Finally, we evaluated the balance between the game and the educational aspects of the game (i.e., the gain in caregiver skills) based on the suggestions of the Icura User Study [60]. Figure 9 depicts the effectiveness of our educational model. Most participants (82\%) confirmed the educational benefits of the serious game and claimed that overall game-based education was effective. Only $9 \%$ of the participants indicated a lower educational effectiveness of the game. 


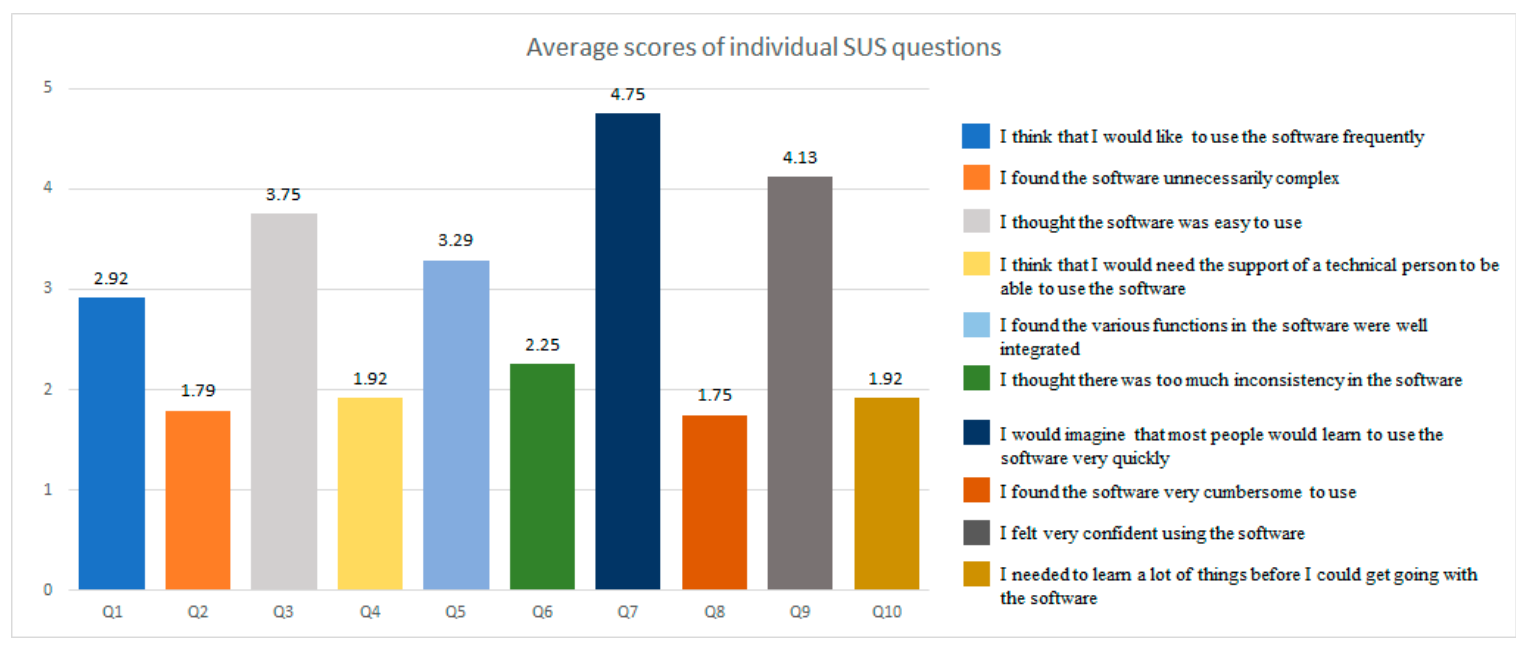

Figure 8. Average scores of individual responses to System Usability Scale (SUS) statements.

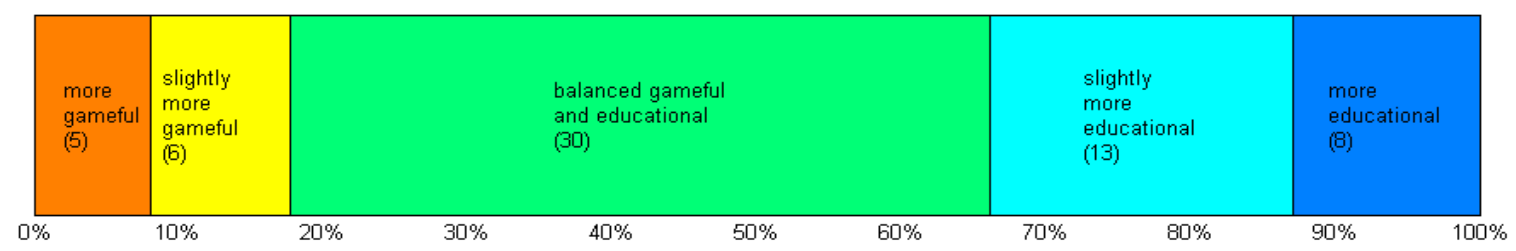

Figure 9. Perception of balance between game and education in the game.

\section{Discussion and Conclusions}

The change in attitudes of persons with dementia and caregivers was assessed via the Dementia Attitudes Scale (DAS). The direct effect of the proposed iDO game was assessed through the Geriatric Depression Scale (GDS) questionnaire. The seniors' GDS scores showed a decrease in negative answers (in percentage) from $24.9 \%$ in the pre-game survey to $10.9 \%$ in the post-game GDS survey. The caregivers' GDS scores showed a decrease in negative answers (in percentage) from $13.4 \%$ in the pre-game survey to $5.2 \%$ in the post-game GDS survey, leading to the conclusion that the game aroused a general increase in positive moods for future caregivers of the target persons with dementia. The overall DAS scores increased from 6.07 (pre-game survey) to 6.41 (post-game survey), as the recorded attitudes were generally positive, indicating a more relaxed status and a decreased fear in accomplishing the caring process. The differences between the results of the pre-game survey and the post-game survey were statistically significant for both caregivers and seniors.

The direct impact of the proposed iDO game showed a significantly positive increase in attitudes and decrease in anxiety of both caregivers (formal and informal) and seniors from pre- to post-game survey. The specifically designed interactive serious game iDO makes it possible to educate/familiarize caregivers to increase their knowledge and, consequently, their confidence in being around people with dementia. Our results showed that formal and informal caregivers of people with dementia who educate themselves through a serious game experience less feelings of fear and distress when being around persons with dementia. The caregivers felt more relaxed with their newly gained knowledge as well as increased confidence. This is in line with the observations of Phillipson et al. [61], who found four hallmarks for successful knowledge translation regarding dementia-oriented education. One of those hallmarks was based on interactive knowledge exchange rather than passive approaches such as lectures. Interactive knowledge was applied in the serious iDO game where the caregivers used their newly learned background knowledge to respond to the person with dementia's needs (e.g., hunger, rest, activity) and neuropsychiatric symptoms to maintain or increase the person's quality of life. The serious game iDO was developed with evidence-based knowledge for formal and informal caregivers caring for people with dementia living at home. A similar serious game was previously developed by Manera et 
al. [62] for people with dementia living in a nursing home. The result of this study showed that it is possible to positively change the attitudes of caregivers caring for persons with dementia. This was also shown in a study which addressed the problem of training hospital staff for person-centered dementia care. The staff significantly improved their attitudes towards and overall satisfaction in caring for people with dementia [63]. Serious games seem to be an easy and playful future tool to educate both formal and informal caregivers and train them how to approach and care for people with dementia living at home or in a nursing home. They can also contribute to reducing the burden for informal caregivers and preventing the rise of negative attitudes and worsening of the caregiver's psychological state [64]. In turn, this seems to result in an improved person-centered care, in that the person with dementia feels less anxious and frustrated.

The impact of using the iDO game was to educate/familiarize caregivers with upcoming care processes. They thus can be indirectly represented as (1) measurably improved confidence and job satisfaction; (2) more effective familiarization and adoption of best practices for dementia care; (3) enhanced overall quality of care; and (4) decreased caregiver burden, fear, and anxiety. The improvements for people with dementia may be (1) person-centered care; (2) less severe NPI scores; (3) increased possibility of building trusting relationships with the caregiver; and (4) enablement of socialization.

Finally, the iDO game contributed to cognitive stimulation (through game playing) and promotion of social interaction which is considered a major function of future technology-supported caregiving and management of dementia [65].

Further investigations are necessary in order to find out whether the game is immersive enough to serve as a motivating tool for formal and informal caregivers. The questions related to the system learnability property received the highest assessments. We can conclude that the selected game type, rules, and mechanics allowed for quick immersion and is in need of further testing.

Author Contributions: Conceptualization, R.M. and R.D.; Data curation, R.M.; Formal analysis, R.D.; Investigation, M.C. and V.A.; Methodology, R.M. and R.D.; Software, A.P.; Validation, A.E., M.C. and V.A.; Visualization, R.M. and R.D.; Writing—original draft, R.M. and R.D.; Writing—review and editing, C.L. and A.E. The total contributions of the authors are as follows: R.M. and R.D.-0.6, M.C. and V.A.-0.1, C.L. and A.E.-0.1, A.P.-0.2.

Funding: Co-funded by the Erasmus programme of the European Union, project-ID: 2017-1-SE01-KA202-034585.

Acknowledgments: The authors would like to thank the IDO consortium members for providing game scenarios and the medical and care specialists involved in the study, especially Kaunas Republican Hospital. This study was conducted within the context of the Centre for Ageing and Supportive Environments (CASE) at Lund University.

Conflicts of Interest: The authors declare no conflict of interest. The funders had no role in the design of the study; in the collection, analyses, or interpretation of data; in the writing of the manuscript, or in the decision to publish the results.

Ethics: The Ethics Board of the KTU Faculty of Informatics approved the studies reported in this journal (referral number EALTV20180222-1). The research complied with the ethical principles for the code of conduct of human-related studies according to the Declaration of Helsinki. Informed consent was obtained from all participants. As their identities were known to the researchers, the respondents signed consent statements.

\section{References}

1. Yusif, S.; Soar, J.; Hafeez-Baig, A. Older people, assistive technologies, and the barriers to adoption: A systematic review. Int. J. Med. Inform. 2016, 94, 112-116. [CrossRef] [PubMed]

2. Siegel, C.; Hochgatterer, A.; Dorner, T.E. Contributions of ambient assisted living for health and quality of life in the elderly and care services-A qualitative analysis from the experts' perspective of care service professionals. BMC Geriatr. 2014, 14, 112. [CrossRef] [PubMed]

3. World Alzheimer Report. The Global Impact of Dementia: An Analysis of Prevalence, Incidence, Cost and Trends; Alzheimer's Disease International: London, UK, 2015.

4. Hardy, C.J.; Marshall, C.R.; Golden, H.L.; Clark, C.N.; Mummery, C.J.; Griffiths, T.D.; Warren, J.D. Hearing and dementia. J. Neurol. 2016, 263, 2339-2354. [CrossRef] [PubMed]

5. Desai, A.K.; Grossberg, G.T. Recognition and Management of Behavioral Disturbances in Dementia. Prim. Care Companion J. Clini. Psychiatry 2001, 3, 93-109. [CrossRef] 
6. Wiloth, S.; Werner, C.; Lemke, N.C.; Bauer, J.; Hauer, K. Motor-cognitive effects of a computerized game-based training method in people with dementia: A randomized controlled trial. J. Aging Ment. Health 2017, 22, 1-12. [CrossRef]

7. Ido Game. Available online: http://idoproject.eu/game/ (accessed on 02 November 2019).

8. Maskeliunas, R.; Damaševicius, R.; Blažauskas, T.; Paulauskas, A.; Paulauskas, L.; Chiatti, C. IDO: Modelling a serious educational game based on hands approach for training dementia carers. Int. J. Eng. Technol. 2018, 7, 143-146. [CrossRef]

9. Deterding, S. Gamification: Designing for motivation. Interactions 2012, 19, 14-17. [CrossRef]

10. Hamari, J.; Koivisto, J. Why do people use gamification services? Int. J. Inf. Manag. 2015, 35, 419-431. [CrossRef]

11. Hamari, J.; Koivisto, J.; Sarsa, H. Does Gamification Work? A Literature Review of Empirical Studies on Gamification. In Proceedings of the 47th Hawaii International Conference on System Sciences (HICSS '14), IEEE Computer Society, Washington, DC, USA, 6-9 January 2014; pp. 3025-3034. [CrossRef]

12. Schoech, D.; Boyas, J.F.; Black, B.M.; Elias-Lambert, N. Gamification for Behavior Change: Lessons from Developing a Social, Multiuser, Web-Tablet Based Prevention Game for Youths. J. Technol. Hum. Serv. 2013, 31, 197-217. [CrossRef]

13. Raziunaite, P.; Miliunaite, A.; Maskeliunas, R.; Damasevicius, R.; Sidekerskiene, T.; Narkeviciene, B. Designing an educational music game for digital game based learning: A Lithuanian case study. In Proceedings of the 2018 41st International Convention on Information and Communication Technology, Electronics and Microelectronics (MIPRO), Opatija, Croatia, 21-25 May 2018; pp. 800-805. [CrossRef]

14. Damaševičius, R.; Narbutaite, L.; Plauska, I.; Blažauskas, T. Advances in the use of educational robots in project-based teaching. TEM J. 2017, 6, 342-348. [CrossRef]

15. Silva, R.; Rodrigues, R.; Leal, C. Play it again: How game-based learning improves flow in Accounting and Marketing education. Account. Educ. 2019, 28, 484-507. [CrossRef]

16. Ašeriškis, D.; Damaševičius, R. Gamification of a project management system. In Proceedings of the 7th International Conference on Advances in Computer-Human Interactions, Barcelona, Spain, 23-27 March 2014; pp. 200-207.

17. Danevičius, E.; Maskeliunas, R.; Damaševičius, R.; Połap, D.; Wožniak, M. A soft body physics simulator with computational offloading to the cloud. Information 2018, 9, 318. [CrossRef]

18. Boyle, E.A.; Hainey, T.; Connolly, T.M.; Gray, G.; Earp, J.; Ott, M.; Lim, T.; Ninaus, M.; Ribeiro, C.; Pereira, J. An update to the systematic literature review of empirical evidence of the impacts and outcomes of computer games and serious games. Comput. Educ. 2016, 94, 178-192. [CrossRef]

19. Almeida, O.P.; Yeap, B.B.; Alfonso, H.; Hankey, G.J.; Flicker, L.; Norman, P.E. Older Men Who Use Computers Have Lower Risk of Dementia. PLoS ONE 2012, 7, e44239. [CrossRef] [PubMed]

20. Petit dit Dariel, O.J.; Raby, T.; Ravaut, F.; Rothan-Tondeur, M. Developing the Serious Games potential in nursing education. Nurse Educ. Today 2013, 33, 1569-1575. [CrossRef]

21. Romero, M. Work, Games and Lifelong Learning in the 21st Century. Proc. Soc. Behav. Sci. 2015, 174, $115-121$. [CrossRef]

22. Johnsen, H.M.; Fossum, M.; Vivekananda-Schmidt, P.; Fruhling, A.; Slettebø, Å. Developing a Serious Game for Nurse Education. J. Gerontol. Nurs. 2018, 44, 15-19. [CrossRef]

23. Bellotti, F.; Kapralos, B.; Lee, K.; Moreno-Ger, P.; Berta, R. Assessment in and of Serious Games: An Overview. Adv. Hum. Comput. Interact. 2013, 2013, 136864. [CrossRef]

24. Laamarti, F.; Eid, M.; El Saddik, A. An Overview of Serious Games. Int. J. Comput. Games Technol. 2014, 2014, 358152. [CrossRef]

25. Manera, V.; Brousse, J.; Foulon, P.; Deudon, A.; Leone, E.; David, R.; Robert, P. Neuropsychiatric symptoms in dementia. How serious games can improve caregiver's education. Innov. Glob. Health Prof. Educ. 2016. [CrossRef]

26. Verkuyl, M.; Romaniuk, D.; Atack, L.; Mastrilli, P. Virtual Gaming Simulation for Nursing Education: An Experiment. Clin. Simul. Nurs. 2017, 13, 238-244. [CrossRef]

27. Pront, L.; Müller, A.; Koschade, A.; Hutton, A. Gaming in Nursing Education: A Literature Review. Nurs. Educ. Perspect. 2018, 39, 23-28. [CrossRef] [PubMed]

28. McCallum, S.; Boletsis, C. Dementia Games. In Serious Games Development and Applications; Ma, M., Oliveira, M.F., Petersen, S., Hauge, J.B., Eds.; Springer: Berlin, Germany, 2013; pp. 15-27. 
29. Zheng, J.; Chen, X.; Yu, P. Game-based interventions and their impact on dementia: A narrative review. Aust. Psychiatry 2017, 25, 562-565. [CrossRef]

30. Tan, A.J.Q.; Lau, C.C.S.; Liaw, S.Y. Serious games in nursing education: An integrative review. In Proceedings of the 9th International Conference on Virtual Worlds and Games for Serious Applications (VS-Games), Athens, Greece, 6-8 September 2017. [CrossRef]

31. Padilha, J.M.; Machado, P.P.; Ribeiro, A.; Ramos, J.; Costa, P. Clinical Virtual Simulation in Nursing Education: Randomized Controlled Trial. J. Med. Internet Res. 2019, 21, e11529. [CrossRef] [PubMed]

32. Mili, F.; Barr, J.; Harris, M.; Pittiglio, L. Nursing Training: 3D Game with Learning Objectives. In Proceedings of the First International Conference on Advances in Computer-Human Interaction, Sainte Luce, Martinique, 10-15 February 2018.

33. Cook, N.F.; McAloon, T.; O'Neill, P.; Beggs, R. Impact of a web based interactive simulation game (PULSE) on nursing students' experience and performance in life support training-A pilot study. Nurse Educ. Today 2012, 32, 714-720. [CrossRef]

34. Tresser, S. Case Study: Using a Novel Virtual Reality Computer Game for Occupational Therapy Intervention. Teleoperators Virtual Environ. 2012, 21, 359-371. [CrossRef]

35. Johnsen, H.M.; Fossum, M.; Vivekananda-Schmidt, P.; Fruhling, A.; Slettebø, Å. A Serious Game for Teaching Nursing Students Clinical Reasoning and Decision-Making Skills. Stud. Health Technol. Inform. 2016, 225, 905-906. [CrossRef]

36. Sisarica, A.; Maiden, N.; Morosini, D.; Panesse, L.; Pudney, K.; Rose, M. Creativity support in a serious game for dementia care. In Proceedings of the 9th ACM Conference on Creativity \& Cognition-C\&C '13, Sydney, Australia, 17-20 June 2013.

37. Wehbe-Alamah, H.; Farmer, M.E.; McFarland, M.; Tower, A.; Jones, M.; Shah, V.; El-Hayek, J. Development of an extensible game architecture for teaching transcultural nursing. Online J. Cult. Competence Nurs. Healthc. 2015, 5, 64-74. [CrossRef]

38. Patel, R.; Salata, A. Using computer games to mediate caregiver-child communication for children with severe dysarthria. J. Med. Speech 2006, 14, 279-284.

39. James, S.; Ziviani, J.; King, G.; Boyd, R.N. Understanding Engagement in Home-Based Interactive Computer Play: Perspectives of Children with Unilateral Cerebral Palsy and Their Caregivers. Phys. Occup. Ther. Pediatr. 2015, 36, 343-358. [CrossRef]

40. Vidani, A.C.; Chittaro, L.; Carchietti, E. Assessing Nurses' Acceptance of a Serious Game for Emergency Medical Services. In Proceedings of the 2nd International Conference on Games and Virtual Worlds for Serious Applications (VS-GAMES 2010), Braga, Portugal, 25-26 March 2010.

41. Wingham, J.; Adie, K.; Turner, D.; Schofield, C.; Pritchard, C. Participant and caregiver experience of the Nintendo Wii SportsTM after stroke: Qualitative study of the trial of WiiTM in stroke (TWIST). Clin. Rehabil. 2014, 29, 295-305. [CrossRef] [PubMed]

42. Xu, Q.; Chen, L.; Zhu, T.; Xu, Y. Assessing the Effect of Game System for Rehabilitation on Rehabilitation of Autism and Cerebral Palsy. MATEC Web Conf. 2015, 22, 1023. [CrossRef]

43. Tak, S.H.; Beck, C.; Hong, S.H. Feasibility of providing computer activities for nursing home residents with dementia. Non Pharmacol. Ther. Dement. 2013, 3,1-10.

44. Tong, T.; Chan, J.H.; Chignell, M. Serious Games for Dementia. In Proceedings of the 26th International Conference on World Wide Web Companion-WWW '17 Companion, Perth, Australia, 3-7 April 2017.

45. Mubin, O.; Shahid, S.; Abdullah Al Mahmud, A. Walk 2 Win: Towards designing a mobile game for elderly's social engagement. In Proceedings of the 22nd British HCI Group Annual Conference on People and Computers: Culture, Creativity, Interaction-Volume 2 (BCS-HCI '08), Liverpool, UK, 1-5 September 2008.

46. Vallejo, V.; Tarnanas, I.; Yamaguchi, T.; Tsukagoshi, T.; Yasuda, R.; Müri, R.M.; Mosimann, U.P.; Nef, T. Usability assessment of natural user interfaces during serious games: Adjustments for dementia intervention. J. Pain Manag. 2016, 9, 333-339.

47. Sardi, L.; Idri, A.; Fernández-Alemán, J.L. A systematic review of gamification in e-Health. J. Biomed. Inf. 2017, 71, 31-48. [CrossRef]

48. Wiemeyer, J.; Kliem, A. Serious games in prevention and rehabilitation-A new panacea for elderly people? Eur. Rev. Aging Phys. Act. 2011, 9, 93. [CrossRef] 
49. Elaachak, L.; Belahbib, A.; Bouhorma, M. A digital revolution in Nursing Education—The serious games. In Proceedings of the 2016 5th Int. Conference on Multimedia Computing and Systems (ICMCS), Marrakech, Morocco, 29 September-1 October 2016; pp. 705-709.

50. Cant, R.P.; Cooper, S.J. Simulation-based learning in nurse education: Systematic review. J. Adv. Nurs. 2010, 66, 3-15. [CrossRef]

51. Ranchhod, A.; Gurău, C.; Loukis, E.; Trivedi, R. Evaluating the educational effectiveness of simulation games: A value generation model. Inf. Sci. 2014, 264, 75-90. [CrossRef]

52. Ašeriškis, D.; Damaševičius, R. Gamification Patterns for Gamification Applications. Procedia Comput. Sci. 2014, 39, 83-90. [CrossRef]

53. Dormans, J. The Effectiveness and Efficiency of Model Driven Game Design. In Proceedings of the 11th international conference on Entertainment Computing (ICEC'12), Bremen, Germany, 26-29 September 2012; pp. 542-548.

54. Carpenter, B.D.; Xiong, C.; Porensky, E.K.; Lee, M.M.; Brown, P.J.; Coats, M.; Johnson, D.; Morris, J.C. Reaction to a dementia diagnosis in individuals with Alzheimer's disease and mild cognitive impairment. J. Am. Geriatr. Soc. 2008, 56, 405-412. [CrossRef]

55. Yesavage, J.A.; Brink, T.L.; Rose, T.L.; Lum, O.; Huang, V.; Adey, M.; Leirer, V.O. Development and validation of a geriatric depression screening scale: A preliminary report. J. Psychiatr. Res. 1982, 17, 37-49. [CrossRef]

56. O'Connor, M.L.; McFadden, S.H. Development and Psychometric Validation of the Dementia Attitudes Scale. Int. J. Alzheimer Dis. 2010, 2010, 454218. [CrossRef]

57. Brooke, J. SUS-A quick and dirty usability scale. Usab. Eval. Ind. 1996, 189, 4-7.

58. Derrick, B.; White, P. Comparing Two Samples from an Individual Likert Question. Int. J. Math. Stat. 2017, 18, 1-13.

59. Dietlein, C.; Bock, O. Usability of serious games for the training of people with dementia. EAI Endorsed Trans. Game Based Learn. 2018, 2018, 159946. [CrossRef]

60. Mortara, M.; Catalano, C.E.; Fiucci, G.; Derntl, M. Evaluating the Effectiveness of Serious Games for Cultural Awareness: The Icura User Study. In International Conference on Games and Learning Alliance; De Gloria, A., Ed.; Springer: Cham, Switzerland, 2013.

61. Phillipson, L.; Goodenough, B.; Reis, S.; Fleming, R. Applying Knowledge Translation Concepts and Strategies in Dementia Care Education for Health Professionals: Recommendations from a Narrative Literature Review. J. Contin. Educ. Health Prof. 2016, 36, 74-81. [CrossRef]

62. Manera, V.; Petit, P.D.; Derreumaux, A.; Orvieto, I.; Romagnoli, M.; Lyttle, G.; David, R.; Robert, P.H. 'Kitchen and cooking', a serious game for mild cognitive impairment and Alzheimer's disease: A pilot study. Front. Aging Neurosci. 2015, 7, 24. [CrossRef]

63. Surr, C.A.; Smith, S.J.; Crossland, J.; Robins, J. Impact of a person-centred dementia care training programme on hospital staff attitudes, role efficacy and perceptions of caring for people with dementia: A repeated measures study. Int. J. Nurs. Stud. 2016, 53, 144-151. [CrossRef]

64. Chiao, C.Y.; Wu, H.S.; Hsiao, C.Y. Caregiver burden for informal caregivers of patients with dementia: A systematic review. Int. Nurs. Rev. 2015, 62, 340-350. [CrossRef]

65. Astell, A.J.; Bouranis, N.; Hoey, J.; Lindauer, A.; Mihailidis, A.; Nugent, C.; Robillard, J.M. Technology and Dementia: The Future is Now. Dement. Geriatr. Cognit. Disord. 2019, 47, 131-139. [CrossRef] 